\title{
Cidade, Educação e Políticas Públicas: Qual o Espaço da Educação Não Formal e Informal nas Políticas Educacionais?
}

\author{
Reinaldo Pacheco* \\ Lazer e Turismo \\ Escola de Artes, Ciências e Humanidades da Universidade de São Paulo \\ * Autor para correspondência: repacheco@usp.br
}

\begin{abstract}
RESUMO
A Escola de Artes, Ciências e Humanidades da Universidade de São Paulo (EACH-USP) caracteriza-se pela oferta de dez cursos diferentes que contam com um ano inicial, com o objetivo da formação humana abrangente, que denominamos de Ciclo Básico (CB). Dentro do $\mathrm{CB}$, algumas disciplinas buscam cumprir esse papel de educação ampliada e compreensão da sociedade contemporânea, dentre elas a disciplina denominada Estudos Diversificados (ED). Nessa disciplina, os docentes são estimulados a oferecer aos estudantes cursos com temáticas abrangentes que permitam a reflexão crítica sobre a sociedade contemporânea. A presente comunicação busca mostrar a experiência de oferta de uma dessas disciplinas de ED, denominada Cidade, Educação e Políticas Públicas, cujo principal questionamento é a compreensão reducionista que as políticas educacionais apresentam acerca do conceito de educação, desconsiderando a potencialidade cidadã das práticas formais e informais. Elegeram-se como objetivos específicos desse ED: a) proporcionar aos estudantes uma visão ampliada do processo educacional formal, não formal e informal e da convergência desse processo com a problemática do uso dos espaços públicos urbanos; b) permitir aos estudantes a observação e o registro, por meio de fotos e vídeos, com produção de documentários audiovisuais, das oportunidades de educação que ocorrem na experiência urbana metropolitana.
\end{abstract}

Palavras-chave: Ensino Superior; Educação Não Formal; Políticas Educacionais.

\begin{abstract}
The School of Arts, Sciences and Humanities of the University of São Paulo (EACH-USP) is characterized by offering ten different courses that have an initial year with the goal of comprehensive human development, called Basic Cycle (CB). Within the $\mathrm{CB}$, some disciplines seek to fulfil this role in a broad education and understanding of contemporary society, among them the discipline called Diversified Studies (ED). In this course, teachers are encouraged to provide students with comprehensive thematic courses that allow this critical reflection on contemporary society. This communication seeks to show the one offering the experience of these ED disciplines, called City, Education and Public Policy whose main challenge is the reductionist understanding that educational policies have on the concept of education, disregarding citizen potential of formal practices and informal. Was elected as a specific objective of this ED: a) give students a broader view of formal education, non-formal and informal and the convergence of this process with the problem of the use of urban public spaces; b) allow students to observe and record, through photos and videos, with production of audio-visual documentaries, educational opportunities that occur in the metropolitan urban experience.
\end{abstract}

Keywords: Higher Education; Non-Formal Education; Educational Policies.

\section{Introdução}

A Escola de Artes, Ciências e Humanidades (EACH) da Universidade de São Paulo (USP) começou a funcionar em 2005, oferecendo dez cursos diferentes dos já ofertados em suas outras unidades espalhadas sobretudo pela cidade de São Paulo e também em algumas cidades do interior paulista. A estrutura planejada para essa nova unidade partiu do princípio não apenas da oferta de cursos diferenciados, mas também da construção de uma unidade que não fosse segmentada por departamentos, favorecendo o contato interdisciplinar e multidisciplinar, de tal maneira que, mesmo em cursos tão diferentes como Têxtil e Moda e Lazer e Turismo, estudantes 
e professores fossem estimulados a buscar formas de contato e aproximação, seja por meio da pesquisa, extensão de serviços culturais e comunitários ou mesmo pelo ensino. Neste último plano, foi elaborado um projeto de Ciclo Básico (CB) no qual os estudantes realizam, notadamente no seu primeiro ano de curso, uma série de atividades pedagógicas em contato com estudantes e professores das várias áreas de conhecimento. Pode-se imaginar o tamanho do desafio de conjugar um currículo de ciclo básico para carreiras tais como as duas já citadas, como também Sistemas de Informação, Obstetrícia, Ciências da Atividade Física, Gerontologia, Licenciatura em Ciências da Natureza, Gestão Ambiental, Gestão de Políticas Públicas e Marketing. Carreiras tão diversas a abrigar um corpo docente também multifacetado, com mais de 260 doutores nas mais variadas áreas.

Dentro dessa experiência de currículo básico para os estudantes ingressantes, pode-se destacar a oferta de disciplinas para a formação ampla e humanista, tais como os chamados Estudos Diversificados (ED). Nessa disciplina, os docentes são estimulados a oferecer aos ingressantes experiências educacionais múltiplas que contemplem formatos e conteúdos diversificados que auxiliem na compreensão da experiência de vida na sociedade contemporânea. A disciplina tem uma carga horária de cerca de trinta horas/aula moduladas em quinze encontros. Como objetivo amplo, na sua ementa a disciplina apresenta os seguintes objetivos: 1) permitir o acesso a diferentes conteúdos culturais, acadêmicos e científicos, por meio de aulas magnas, pesquisas na biblioteca e na internet, conferências, seminários, mesas-redondas, trabalhos em grupo e individuais; 2) possibilitar o trabalho e o aprendizado sistematizado sobre conteúdos em que estudantes e professores sintam que se enriquecerá a vida acadêmica, por meio de oficinas de português, língua estrangeira, ciências, informática, artes plásticas, visuais, cênicas, musicais, corporais, atividades físicas, rádio e TV comunitária, dentre outras. Pode-se perceber que as possibilidades de composição de um programa de estudos e atividades se tornam bastante abrangentes em vista de tais objetivos. Pensando nisso, buscou-se propor um ED que discutisse, na experiência da vida urbana contemporânea, como as práticas de educação não formal e informal surgem e se manifestam, e tentar responder à seguinte indagação: de que forma as políticas educacionais tratam as práticas de educação não formal e informal? Essas práticas são consideradas dentro da agenda de definição de investimentos e prioridades das políticas educacionais? Nossa hipótese, obviamente, era a de que as políticas educacionais sequer tangenciam a temática do não formal e informal, privilegiando sobremaneira a chamada educação formal, escolar.

Para dar conta do desafio de tentar, junto com os estudantes ingressantes, investigar essa questão, buscou-se estabelecer os seguintes objetivos para esse ED temático, denominando-o de Cidade, Educação e Políticas Públicas: 1) Proporcionar aos estudantes uma visão ampliada do processo educacional formal e não formal e da convergência desse processo com a problemática do uso dos espaços públicos urbanos; 2) Permitir aos estudantes a observação e o registro, por meio de fotos e vídeos, com produção de documentários audiovisuais, das oportunidades de educação não formal que ocorrem na experiência urbana metropolitana.

No entanto, para que estudantes ingressantes pudessem ter parâmetros para a análise da realidade contemporânea e um olhar mais apurado sobre as práticas educacionais não formais e informais, optou-se pela oferta de quase metade das aulas do curso voltadas a encontros de discussão sobre essa temática. São oferecidas atividades em sala de aula (leituras, discussões, aulas expositivas) que abordam os processos educativos não formais existentes na experiência urbana contemporânea. Trata-se de discutir o alcance educacional das políticas públicas de cultura, esportes e lazer, meio ambiente, saúde, dentre outras, e como elas estão plenas de potencialidades educativas, não consideradas pela política educacional "oficial". Busca-se refletir sobre o uso dos espaços públicos como ambientes educacionais, tais como as ruas, praças, centros culturais, centros esportivos, parques públicos, dentre outros. Tal proposta coaduna-se com a proposição dos Estudos Diversificados, cuja ementa prevê que, de comum acordo com os 
estudantes, seja estabelecido um programa de atividades, a partir dos recursos culturais, científicos e acadêmicos disponíveis na universidade e que, sob supervisão docente, cada estudante ou grupo de estudantes possa estabelecer os estudos e atividades que realizará durante o semestre. Ainda assim, em cada ED, as turmas são de cerca de 65 estudantes. Neste caso, optou-se por vários momentos de encontro com o grupo todo para as discussões coletivas e depois orientações mais detalhadas, para que os subgrupos pudessem realizar uma produção audiovisual, registrando formas, processos, instituições e práticas de educação não formal e informal, especialmente nos espaços públicos e nas instituições do chamado Terceiro Setor, na metrópole. Esse registro foi considerado o trabalho final da disciplina.

\section{Detalhando o Curso, o Caminho}

No primeiro encontro do curso é realizada uma avaliação diagnóstica, no sentido de conhecer as experiências anteriores dos estudantes acerca dos processos de educação formal e informal que até então marcaram sua formação: participação em grupos esportivos e artísticos, comunidades religiosas, organizações sociais locais, viagens, dentre outras práticas que ocorreram no âmbito da família ou de grupos sociais próximos e que marcaram a experiência educativa. Além disso, como muitos estudantes são de cidades diferentes da cidade de São Paulo, especialmente de cidades do interior do estado, pede-se para que eles reflitam sobre os espaços e práticas da educação não formal em sua cidade de origem. Os dados coletados são sempre muito interessantes e revelam uma multiplicidade de práticas, que são explicitadas e discutidas com o grupo.

Depois dessa primeira aproximação com o tema, o curso passa a ser conduzido para a discussão sobre o fenômeno urbano. Discutem-se o processo de urbanização como uma questão histórico-social e os problemas sociais daí decorrentes, desde a emergência da modernidade e a partir do marco da Revolução Industrial. São indicadas algumas leituras que fundamentarão a discussão, como o texto da antropóloga Teresa Caldeira (1997), que discute o modelo segregacional de urbanização a que estamos submetidos nas metrópoles brasileiras, erguendo-se "cidade de muros" e construindo-se "enclaves fortificados" que transmitem a falsa sensação de segurança e isolamento das mazelas sociais. Colocam-se algumas questões em discussão para se tentar compreender os quatro processos de mudança nas décadas de 1980 e 1990 que contribuíram para a segregação espacial em São Paulo e lhe marcaram tal padrão: 1) a crise econômica; 2) a reestruturação produtiva global; 3) a abertura democrática; 4) o medo da violência. Pode-se perceber como esses processos irão alterar as relações dos sujeitos com os espaços públicos e privados. Trazendo a discussão para o campo da metrópole paulistana, estudam-se a legislação que permite esse tipo de urbanização (Plano Diretor) e possíveis novas formas de valorização da ocupação do espaço público de forma cidadã (GOTTDIENER, 1983; LEFEBVRE, 1969; MARQUES \& BICHIR, 2002).

Num próximo momento, discute-se a ideia de educação. Sugere-se a leitura dos textos de Vitor Paro (1999) e de Almerindo Afonso (2001). O primeiro, ainda que trate da educação escolar, nos traz uma perspectiva de discussão acerca da abrangência do conceito de educação como um processo permanente, inerente à vida, e não como mera preparação para o trabalho. O segundo autor ilumina para os estudantes o conceito de educação e seus "lugares", múltiplos e diferentes, que vão além do espaço da escola. Usando o conceito de "cidade educadora", permite-se questionar se é possível que a cidade seja preparada para entender seus múltiplos espaços como educativos. Discute o papel das atividades de lazer, cultura, artes, esportes nesse processo (PADILHA, 2006; GELPI, 1983; MAGNANI, 1984, MARCELLINO, 1987; VALLE, 1988).

Dessa maneira, entra-se, finalmente, no campo das políticas públicas e como as cidades poderiam articular as políticas de educação, cultura, esportes, lazer, saúde, meio ambiente, dentre outras, de tal 
forma que vários dos espaços e das proposições de ação do poder público pudessem contemplar uma política pública de educação que não fosse apenas uma política de educação escolar. Portanto, sugerem-se leituras no campo da intersetorialidade das políticas públicas que fundamentam a visão de que novas formas de ação do poder público local são possíveis e necessárias (GOHN, 1999; AZEVEDO, 1997).

$\mathrm{Na}$ última parte do curso, os estudantes são estimulados a pensar como o registro videográfico pode ser uma ferramenta da ciência social (FERRAZ, 1998; PEIXOTO, 1996) e escolhem uma prática, espaço, instituição, manifestação que possa ser considerada uma forma de educação não formal ou informal que ocorre no território da metrópole e que mereceria um registro. São elaborados ensaios videográficos documentais de no máximo cinco minutos de duração.

\section{Breve Análise da Produção Videográfica Discente}

Esta disciplina de Estudos Diversificados foi oferecida em dois semestres diferentes, e a produção videográfica discente incidiu sobre diversos aspectos da educação não formal e informal, com pouco mais de vinte trabalhos. Obviamente, não há que se julgar a qualidade técnica da produção, pois a própria unidade não dispõe de equipamentos em número e qualidade suficientes que permitiriam um resultado técnico com relação à captação de imagens, sons e edição que fosse de melhor qualidade. Ainda assim, alguns estudantes, filhos que são de uma geração "alfabetizada" na linguagem das imagens, conseguem resultados bastante interessantes também do ponto de vista técnico. Faz-se aqui uma breve descrição de alguns dos conteúdos abordados:

1) Aldeia das Artes: organização que mantém espaço com atividades livres no campo das artes, tais como dança, teatro etc. 2) Bike Anjo: interessante grupo que atua auxiliando pessoas que querem aprender a usar a bicicleta no ambiente urbano para seu deslocamento cotidiano. 3) Blogs: experiência de grupos de jovens que se dedicam a criar e manter blogs sobre os mais diferentes assuntos. 4) Cavalete: os cavaletes são usados, no Brasil, para propaganda política em época eleitoral. Relata-se aqui a criação do "cavalete parede", uma intervenção na qual artistas plásticos "sequestram" os cavaletes com propaganda e os transformam em suporte para as artes plásticas. 5) Coleta seletiva: relato sobre grupo que atende catadores de lixo que vivem da reciclagem. 6) Estação Jovem: espaço do terceiro setor com atividades para o público juvenil. 7) Marco - múltipla ação regional comunitária: grupo que busca empreender mudanças em seu bairro. 8) Mímica educativa: intervenção patrocinada pelo poder público para educar pedestres e motoristas com relação ao respeito à faixa de pedestres. 9) Praça Roosevelt: remodelação e reocupação de um espaço público degradado. 10) Teatro vidas: grupo de teatro de bairro. 11) Grafite: grupo de jovens e ótimos depoimentos de como interagem com a metrópole cobrindo muros com arte. 12) Jazz: grupo de músicos que se apresentam na rua. 13) Liberdade: bairro de São Paulo retratado em função de sua feira de domingo, repleta de atividades culturais e gastronômicas. 14) Livro livre: grupo que prega o desprendimento da posse dos livros, espalhando-os pelos espaços públicos. 15) Parque da Juventude: parque público construído onde antes era um presídio. 16) Periferia Invisível - Associação de Arte e Cultura: grupo que realiza diversas atividades artísticas com jovens. 17) Teatro Popular Solano Trindade: grupo de danças populares e teatro coordenado pela família Trindade, importantes na valorização da cultura popular brasileira e da cultura negra em especial. 18) Centro de Apoio ao Desenvolvimento do Empreendedorismo: associação que se dedica a valorizar e estimular a prática do empreendedorismo, especialmente para jovens. 19) Paróquia São Benedito: igreja que realiza diversas atividades comunitárias. 20) Telecentro: projeto público de inclusão digital, usado especialmente por jovens. 21) Fábrica de Cultura: projeto público de difusão de oficinas de arte e cultura em bairros nos quais se identificam jovens em situação de risco social. 22) Centro Espírita: organização religiosa que realiza diversas 
atividades artísticas. 23) Casa de Cultura do Brás: espaço público que organiza oficinas e grupos de arte em determinado bairro da cidade.

\section{Considerações Finais}

Até que ponto as políticas educacionais consideram as práticas educacionais formais $\mathrm{e}$ informais como importantes, significativas e merecedoras de investimentos públicos específicos? Essa foi a questão norteadora desta experiência pedagógica. Pode-se concluir, a partir das discussões e registros, que há uma potencialidade muito evidente das práticas de educação não formal e informal na cidade. Por parte das políticas públicas, parece-nos haver pouco entendimento da importância desses processos na criação de uma cidade mais justa e humana. Uma saída para tal impasse talvez fosse pensar uma política educacional que considerasse não apenas a educação formal no escopo de suas ações.

\section{Referências Bibliográficas}

AFONSO, Almerindo Janela. "Os Lugares da Educação". In: FERNANDES, Renata Sieiro et al (orgs.). Educação Não Formal: Cenários da Criaşão. Campinas: Editora da Unicamp/Centro da Memória, 2001.

AZEVEDO, Janete M. Lins de. A Educação como Política Pública: Polêmicas do Nosso Tempo. Campinas: Autores Associados, 1997.

CALDEIRA, Teresa Pires do Rio. "Enclaves Fortificados: a Nova Segregação Urbana". Novos Estudos Cebrap. São Paulo, n. 47, mar. 1997, pp. 155-176.

FERRAZ, Ana Lucia. "Desafios da Imagem. Fotografia, Iconografia e Vídeo nas Ciências Sociais". Revista de Antropologia USP, São Paulo, vol. 41, n. 2, 1998.
GELPI, Ettore. Lazer e Educaşão Permanente: Tempos, Espacsos, Políticas e Atividades de Educasão Permanente e do Lazer. São Paulo: Sesc, 1983.

GOHN, Maria da Glória. Educaşão Não Formal e Cultura Política: Impactos sobre o Associativismo do Terceiro Setor. São Paulo: Cortez, 1999.

GOTTDIENER, Mark. A Produção Social do Espaço Urbano. São Paulo: Edusp, 1993.

LEFEBVRE, Henri. O Direito à Cidade. São Paulo: Documentos, 1969.

MAGNANI, José Guilherme Cantor. Festa no Pedaço: Cultura Popular e Lazer na Cidade. São Paulo: Brasiliense, 1984.

MARCELLINO, Nelson Carvalho. Lazer e Educação. Campinas: Papirus, 1987.

MARQUES, Eduardo Cesar \& BICHIR, Renata Mirandola. "Investimentos Públicos, Infraestrutura Urbana e Produção da Periferia em São Paulo". Revista Espaço e Debates, n. 42, pp. 9-30, 2002. Disponível em: $<$ http://www.fflch.usp.br/centrodametropole/antigo/ v1/pdf/marques_bichir_esp_deb.pdf $>$. Acessado em: 04 out. 2016.

PADILHA, Valquíria (org.). Dialética do Lazer. São Paulo: Cortez, 2006.

PARO, Vitor Henrique. "Parem de Preparar para o Trabalho!!! Reflexões acerca dos Efeitos do Neoliberalismo sobre a Gestão e o Papel da Escola Básica". In: FERRETTI, Celso João et al (orgs.). Trabalho, Formação e Currículo: para Onde Vai a Escola. São Paulo: Xamã, 1999, pp. 101-120.

PEIXOTO, Clarice. "Do Diário de Campo à Câmera na Mão ou de como Virar Antropólogo Cineasta". Revista de Antropologia USP, São Paulo, vol. 39, n. 2, 1996.

VALLE, Lilian do. "O Lazer como Resistência". Fórum Educacional, Rio de Janeiro, vol. 12, n. 4, out/dez. 1988, pp. 44-50. 